
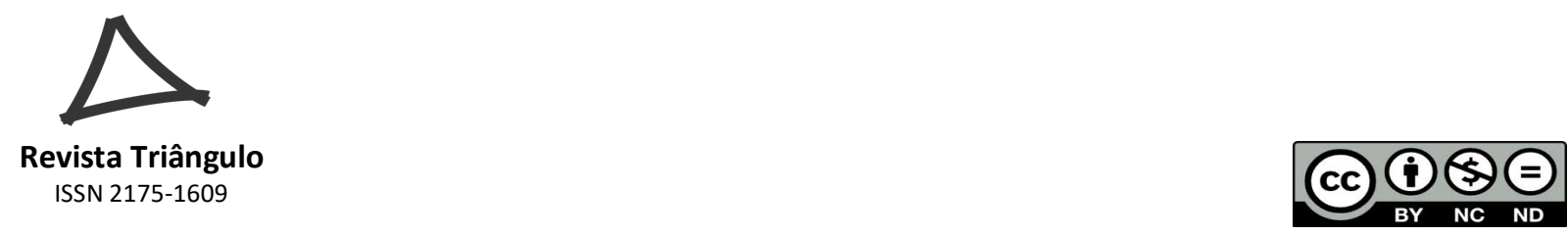

\title{
O PIBID ENQUANTO POLÍtICA EDUCACIONAL: REPERCUSSÕeS PARA A FORMAÇÃO DE PROFESSORES dE EDUCAÇÃO FÍSICA
}

\author{
THE PIBID AND ITS REPERCUSSIONS TO TEACHERS' INITIAL TRAINING IN PHYSICAL \\ EDUCATION
}

\section{EL PIBID ENTONCES POLÍTICA EDUCACIONAL: REPERCUSIONES PARA LA FORMACIÓN DE PROFESORES DE EDUCACIÓN FÍSICA}

\author{
Daiane Dalla Nora \\ E-mail: dallanoradaiane@gmail.com \\ João Francisco Magno Ribas \\ E-mail: ribasjfm@hotmail.com \\ Universidade Federal de Santa Maria - UFSM \\ Agência de fomento: CAPES
}

\begin{abstract}
RESUMO
O objetivo deste estudo consiste em analisar o PIBID enquanto política educacional e suas repercussões para a formação de professores de Educação Física. Para a compreensão do real foi utilizado entrevista semiestruturada, com acadêmicos que participaram do subprojeto, e estão cursando o Mestrado do Programa de Pós-Graduação em Educação Física. Constatou-se que o PIBID - "Cultura esportiva da escola" enquanto política educacional é uma ação compensatória que acaba preenchendo lacunas da formação inicial. Além de ser uma política de adesão individual, própria da política neoliberal, que prejudica e desmobiliza ações coletivas desqualificando a formação de professores de Educação Física.
\end{abstract}

PALAVRAS-CHAVE: Políticas públicas. Educação Física. Educação.

\section{ABSTRACT}

This study aims to analyze the PIBID while educational policy and its repercussions for the teachers' initial training Physical Education. We use semi-structured interviews, with academics that participated in the subproject and they are currently enrolled in the Master's degree of the Postgraduate Program in Physical Education. It was found that the PIBID - "Sporting Culture at School" while educational policy is a compensatory action that ends up filling gaps in the initial training. Besides it is an individual membership policy, own of the neoliberal policy, which harms and demobilizes collective actions disqualifying the teachers, training of Physical Education.

KEYWORDS: Public policies. Physical Education. Education.

\section{RESUMEN}

El objetivo de este estudio consiste en analizar el PIBID como politica educativa y sus repercusiones para la formación de profesores de Educación Física. Para la comprensión de lo real hicimos uso de la entrevista semiestructurada, con académicos que participaron del subproyecto y están cursando el Máster del Programa de Postgrado en Educación Física. Se constató que el PIBID - "Cultura deportiva de la escuela" como política educativa es una acción compensatoria que acaba llenando lagunas de la formación inicial. Además de ser una política de adhesión individual, propia de la política neoliberal, que perjudica y desmoviliza acciones colectivas descalificando la formación de profesores de Educación Física.

PALABRAS-CLAVE: Políticas públicas. Educación Física. Educación. 


\section{INTRODUÇÃ̃O}

A formação inicial em Educação Física deve ser situada no contexto histórico, ou seja, deve-se considerá-la atrelada ao desenvolvimento das relações produtivas capitalistas, cujo objetivo é a exploração da força de trabalho e exige um trabalhador disciplinado. A relação entre trabalho e educação é um fenômeno histórico e social do ser humano, por isso a educação exerceu e continua exercendo um papel central para a readequação dos trabalhadores às novas características do processo produtivo.

Nos dias de hoje, a formação e a universidade são pontos extremamente visados pelo capitalismo, sendo cotidianamente alvos de "ataques" das relações produtivas capitalistas. Assim, a educação enquanto direito passa a ser transformada em "mercadoria", ou seja, cada vez mais vem sofrendo modificações estruturais que a desqualificam, ao prejudicar a classe trabalhadora e privilegiar apenas os detentores do capital.

A formação inicial de professores de Educação Física também está inserida nessa conjuntura atual, em projetos de formação articulados com a lógica do sistema, os quais levam à precarização da formação inicial. E como as demais licenciaturas, conforme Taffarel et al. (2006) a formação em Educação Física apresenta problemas teóricos, epistemológicos, curriculares, de financiamento público, de oferecimento de condições objetivas e problemas políticos.

Neste contexto, observa-se que o governo juntamente com a universidade, busca elaborar programas e políticas, incentivando a criação de ações com o objetivo de solucionar limitações na formação inicial. Neste sentido, nos últimos anos vem incentivando políticas educacionais de formação de professores, dentre elas, o Programa Institucional de Bolsa de Iniciação à Docência (PIBID).

O estudo justifica-se pela necessidade de pesquisas de avaliações do subprojeto "Cultura esportiva da escola" enquanto política pública educacional, uma vez que temos acompanhado o esforço da comunidade acadêmica em estudá-lo com suas produções sendo circuladas em eventos científicos, periódicos, bem como em dissertações.

\section{MATERIAIS E MÉTODOS}

Trata-se de um estudo cuja abordagem é qualitativa, pois entende-se ser do ponto de vista teórico-metodológico o mais indicado para compreender o contexto do PIBID. Na investigação utilizou-se a entrevista semiestruturada, que segundo Minayo (2011, p. 64) "combina perguntas fechadas e abertas, em que o entrevistado tem a possibilidade de discorrer sobre o tema em questão sem se prender à indagação formulada". Fizeram parte deste estudo dez (10) alunos formados em Educação Física. Como critério de seleção dos participantes, optou-se por alunos egressos do Curso de Educação Física - Licenciatura, que participaram do subprojeto entre os anos de 2010, 2011, 2012 e 2013 e são alunos que ingressaram no Curso de Mestrado do Programa de Pós-Graduação em Educação Física nos 
anos de 2012, 2013 e 2014. A seleção justifica-se em razão dos alunos se encontrarem em processo de formação continuada, que possibilita a experiência dos sujeitos nos diferentes contextos, o escolar e a universidade.

A coleta de informações foi realizada por meio de entrevista pré-agendada, no período de março a junho de 2014. As entrevistas foram registradas em áudio e transcritas na íntegra. A transcrição da entrevista foi entregue aos colaboradores para que fizessem a leitura e verificassem a clareza das informações. Todas as informações foram armazenadas na sala 2047, prédio 51, Centro de Educação Física e Desportos da UFSM. O estudo foi aprovado pelo Comitê de Ética em Pesquisa da universidade, o número do parecer ou protocolo de aprovação é CAAE: 33985014.5.0000.5346.

As perguntas que orientaram a entrevista semiestruturada foram estabelecidas a partir de questões norteadoras estruturadas nos seguintes blocos: Bloco 1: Dados de identificação; Bloco 2: Compreensão dos participantes quanto ao trabalho pedagógico realizado no subprojeto; Bloco 3: Implicações do trabalho pedagógico no PIBID - "Cultura esportiva da escola" para a formação inicial. Para análise dos dados utilizou-se os princípios da Análise de Conteúdo, técnica que permitiu analisar e fazer interferências (BARDIN, 2011).

\section{O PIBID NO CONTEXTO DAS POLÍticAS EDUCACIONAIS PARA A FORMAÇÃO DE PROFESSORES}

O Programa Institucional de Bolsa de Iniciação à Docência - PIBID, instituído pelo Ministério da Educação - MEC e, financiado pela Coordenação de Aperfeiçoamento de Pessoal de Nível Superior - CAPES, busca valorizar as ações dos acadêmicos de licenciatura, aproximando os futuros professores da escola, a fim de contribuir para a melhoria da qualidade do ensino público.

O subprojeto "Cultura Esportiva da Escola" tem como foco de ação a criação de um campo de atuação na docência na escola de educação básica aos futuros educadores em formação inicial (acadêmicos da graduação em Licenciatura em Educação Física da UFSM) e formação continuada (professores das escolas e do curso de graduação em Educação Física da UFSM), desenvolvendo práticas educacionais e construindo estratégias educacionais inovadoras na área da Educação Física escolar.

Os acadêmicos em formação (bolsistas do PIBID) são subsidiados por toda uma estrutura e rede de apoio constituída pelos professores do curso de graduação, professores da escola, orientador do subprojeto, alunos da escola, comunidade escolar e o suporte de equipamentos e materiais previstos, estimulando-os a desenvolver estratégias pedagógicas educacionais diretamente no campo de intervenção, a escola, a partir da realidade existente e suas problemáticas com vistas à busca de alternativas pelo coletivo dos envolvidos no processo educacional.

O subprojeto em sua essência privilegia a participação do coletivo em suas ações/intervenções através da realização semanal de estudos com o objetivo de dialogar com 
os diferentes atores, buscando resgatar o sentido e o significado de dialogar com os vários espaços da cultura esportiva escolar e seu entorno, buscando dar sentido e significado educativo no espaço educacional.

Porém, ao indagarmos como os alunos percebem o PIBID - "Cultura esportiva da escola" enquanto política educacional, evidenciou-se como principais pontos negativos os relacionados a uma política de adesão individual e compensatória.

Para sete (7) alunos colaboradores do estudo, o PIBID se constitui em uma política de adesão individual. O Aluno A expõe que o subprojeto "Cultura esportiva da escola" foi bom para a formação inicial dos bolsistas que participaram dele, porém a maioria dos alunos do Centro de Educação Física e desportos - CEFD, que não pode participar, o subprojeto não trouxe nenhum benefício. "Se não está elencado com o projeto político pedagógico da instituição não vai contribuir em nada para aqueles, porque para aqueles é como se o projeto não existisse e aqueles são a grande maioria” (ALUNO A).

O PIBID é uma política absolutamente de adesão individual, que tem a ver com a lógica de política neoliberal, que estimula a individualidade e a competitividade, na qual o projeto, a instituição, a escola, os professores e os alunos se inserem somente se os mesmos são aprovados nos editais do processo seletivo. Isso prejudica qualquer outro processo de ação coletiva, na busca de uma qualidade que abranja a todos, caracterizando-se como uma política neoliberal que têm como caminho a individualização. Segundo Santos Júnior (2005) constitui-se a ferramenta pedagógica do neoliberalismo, uma vez que apresenta como característica:

[...] a ênfase no individualismo (responsabilizando cada uma na sua formação); exacerbação da competição (quebrando a noção de categoria visto que não há mais uma política global de formação, mas sim, um rol de competências para se disputar a fim de estar "melhor qualificado" no sentido da empregabilidade) (p. 56-57).

Para um (1) dos entrevistados, o subprojeto se insere na lógica da culpabilização, na qual a responsabilidade da formação depende sempre do indivíduo. Assim, se o acadêmico não conseguir um melhor aproveitamento, a culpa é dele, ou seja, independe se o bolsista é formado num curso que é deficiente, seu sucesso ou insucesso profissional é de sua responsabilidade apenas.

Para o aluno B essa política de governo, agora de Estado, pode representar uma ameaça para e educação superior como relata na seguinte fala:

Eu tenho medo, eu fiquei sabendo a pouco tempo que virou uma política de Estado, ao mesmo tempo que tenho medo quando fica só política de governo porque tem muitas políticas que são boas e muitas vezes não dão continuidade, só que ao mesmo tempo que eu vejo que quando viram uma política de Estado não dá para negar que o governo que vai vir depois vai colocar a sua cara no projeto, o que eu quero dizer com isso: ele vai colocar seu viés e se por exemplo vem um governo, hoje o governo Lula/Dilma que é uma continuidade ele tem caráter neoliberal de privatizações (ALUNO B). 
Evidencia-se que o PIBID é uma política de Estado, mas na verdade possui características de uma política de governo, assim como muitas políticas educacionais que iniciam como política de governo e viram políticas de Estado, acaba tomando "cara" de política de governo. Desde a década de 90, as políticas educacionais têm tido um caráter "minimalista", como exemplo a LDB, entre outras. As políticas são flexíveis e se moldam muito facilmente ao que está colocado pelo sistema. Percebe-se que o PIBID atualmente se constitui numa política que adentra nessa lógica neoliberal minimalista, das leis minimalistas e que possibilitam duplas interpretações, ela vai se adaptando ao que os governos querem, como expressa a seguinte fala:

É meio que um "assistencialismo", também é uma politica de governo. Se esse governo que está agora implementou e criou isso e está dando maiores bolsas que a Universidade já teve para a licenciatura pelo menos que sempre foi relegada as menores bolsas vai perder, porque acaba que tendo o pessoal na mão, se eu sair do governo não vai ter mais PIBID, não vai ter Mais Educação, não vai ter mais bolsa familia, não vai ter bolsa escola, então é uma forma de "assistencialismo" assim, que também ajuda, mas ele poderia avançar mais na verdade, ele poderia se relacionar com o currículo (ALUNO E).

O PIBID veio como uma forma paliativa assim de suprir essa necessidade, ao invés da escola oferecer um turno integral de ensino, ela só oferece meio turno e o outro meio turno vem com esse projeto para dar conta do papel que não tem, mas deveria $\operatorname{ter}(A L U N O J)$.

Em segundo lugar, os alunos apontam o PIBID como uma política compensatória, para amenizar a precarização da formação de professores, uma forma imediata de suprir as lacunas da formação inicial. Eles consideram que somente os estágios curriculares não são suficientes, são poucas horas e pouco contato com a escola, sendo o subprojeto muito importante para a formação, como expressa a seguinte fala:

Claro tu tem nos estágios o estudo do PPP, mas é teoria, a gente não tem aquela coisa da prática, de trabalhar, de chegar, falar com um pai, falar com o aluno, falar com os outros professores. Então é isso que eu penso, que ele dá um embasamento bem forte pra gente, de chegar na escola e ter uma tranquilidade maior pra trabalhar depois de formado (ALUNO 8).

Para o Aluno G, mesmo com o subprojeto, as lacunas na formação inicial se mostram deficitárias, essa demanda ainda não foi suprida, ele questiona-se "se o PIBID acabar como vai ficar a formação inicial? Quais são os benefícios ao longo prazo que o PIBID vai trazer para a formação inicial em busca de uma melhor qualificação na formação inicial?"

De acordo com Puiati (2014, p. 9), a relação estabelecida pelos alunos bolsistas, entre os cursos de licenciaturas e os subprojetos PIBID/CAPES/UFSM "são de compensação: o 
PIBID parece estar suprindo lacunas dos cursos de licenciaturas, a mais importante dessas lacunas refere-se ao desenvolvimento de atividades práticas em escolas".

Para Taffarel (2012, p. 99) essas políticas compensatórias, que focam nos "mínimos" fragilizando a formação dos trabalhadores para ampliar lucros do capital.

\begin{abstract}
Estes mecanismos incidem sobre a classe trabalhadora, para desqualificá-la no processo de formação e, assim, melhor explorá-la. Um destes mecanismos é a divisão na formação acadêmica, que fragiliza, pelo esvaziamento teórico, a formação dos trabalhadores. O outro é na inserção e atuação nos campos de trabalho, delimitando a atuação e, com isto, restringindo a intervenção da classe trabalhadora nos campos de trabalho. O aparato legal daí decorrente é resultante, portanto, da economia política e das leis gerais que regem o capitalismo.
\end{abstract}

Quando indagados sobre os pontos positivos dessa política, todos os alunos relataram a aproximação da realidade escolar como ponto positivo do PIBID. Para os alunos, a iniciação à docência é uma experiência ótima para a formação inicial, uma vez que muitos acadêmicos do curso de Educação Física vão para a escola sem ter um conhecimento da realidade escolar e muitos professores da Universidade também não conhecem a realidade escolar. Para o aluno D, os professores "falam de uma utopia que criam na mente ou numa escola particular, mas ele não conhecem a escola de periferia a qual a gente trabalha, na escola do morro eles não conhecem a realidade escolar e eu acho que enquanto política poderiam melhorar às vezes a formação inicial do acadêmico".

Outro ponto positivo elencado por seis (6) alunos é a articulação entre teoria e prática estabelecida no PIBID, uma vez que dentre as lacunas da formação inicial está a falta de articulação entre teoria e prática, uma questão bastante complexa. No subprojeto essa articulação se dá de forma mais satisfatória se comparada com a formação inicial. $O$ subprojeto possibilitou "tanto teoria quanto prática, ele traz um embasamento bem significativo para nossa formação, importante que ele siga, tem que se aproximar mais da escola e possibilitar essas idas nossas, dos graduandos para escola" (ALUNO H).

Percebe-se que o aluno aprende a partir dessa articulação entre teoria e prática. Por isso, há a necessidade do acadêmico estar inserido no contexto escolar desde o início do curso. De acordo com o Relatório 2009-2013 da CAPES os licenciandos do programa avaliam o PIBID da seguinte forma:

Articular teoria e prática; Aproximar os licenciandos do contexto da escola básica desde o início do curso de licenciatura; Proporcionar formação qualificada aos licenciandos; Conhecer/usar metodologias aplicadas; Questionar a qualidade das práticas formativas no âmbito da docência; Estimular os licenciandos a buscar soluções, planejar e desenvolver atividades de ensino /pesquisa e elaboração de materiais didáticos; Estimular os licenciandos para realizar pesquisa, participar de eventos científicos ou de cursos de pós-graduação; Valorizar a docência por parte dos licenciandos; Diminuir a evasão e estimular a permanência dos estudantes em uma área de conhecimento; Melhorar a fala, a escrita e a comunicação dos alunos bolsistas (BRASIL, 2013, p. 102). 
Quanto as mudanças para essa política, os alunos propõem as seguintes ações, a principal mudança proposta pelos alunos é relacionar o PIBID com a formação inicial, como expressa o Aluno F "se ele conversasse com a formação e a formação com o PIBID e se também desse oportunidade para mais acadêmicos da formação inicial entrar no PIBID eu acho que seria uma politica excelente".

Segundo Puiati (2014), em estudo realizado com dez (10) subprojetos do PIBID/UFSM, foi constatado essa falta de articulação entre o PIBID e a formação inicial, como expressa:

\footnotetext{
Não há articulações explícitas entre esses dois espaços formativos que são âmbitos de desenvolvimento de ações de iniciação à docência. As poucas associações estabelecidas ocorrem de maneira individualizada: ou mediante iniciativa de um Bolsista de Iniciação à Docência ou, no máximo, por um pequeno grupo deles, no âmbito de um Subprojeto (PUIATI, 2014, p. 9).
}

Para dois (2) alunos o PIBID poderia avançar enquanto disciplina curricular, pois seria mais eficiente se fosse parte da formação e não como uma política, porque, enquanto projeto, ele fica para além da formação, descolado. Para o Aluno E [...] "apesar de ter três estágios e várias práticas de ensino a gente ainda sai com uma debilidade em vivência prática e essas horas em vez de projeto virar disciplina, um projeto que se relacione com um projeto pedagógico curricular". Percebe-se que tornar o subprojeto curricular é uma mudança para a melhoria dessa política educacional.

O Aluno F sugere como mudança o PIBID substituir os estágios, limitando assim o tempo de permanência no subprojeto, para que todos os acadêmicos possam participar das vivências e experiências proporcionadas. "No PIBID tu ganha uma experiência muito maior, porque não para todos os alunos do curso? só esses vinte e quatro vão ter direito a essa vivência prática na escola, realmente se inserir na realidade escolar e o resto?" (ALUNO F). De acordo com Puiati o PIBID:

[...] tem sido a "válvula de escape" para os problemas vividos nos Cursos de Licenciatura. É essa a única relação explícita que percebemos entre Cursos de Licenciatura e programa PIBID, ou seja, uma relação de compensação: o PIBID parece estar suprindo lacunas dos Cursos de Licenciatura (PUIATI, 2014, p. 159).

Entende-se que as novas políticas educacionais não vêm possibilitando avanços consistentes na formação de professores de Educação Física. Nas Diretrizes Curriculares Nacionais para a Educação Física - DCNEF observa-se que o processo de formação de professores está centrado no desenvolvimento de competências, as quais constituem uma formação individualista e buscam a certificação do professor de Educação Física, com concepção mercadológica, tecnicista, fragmentada, desqualificando-o. Dessa maneira, o 
PIBID é entendido como política educacional, inserida na organização do trabalho e diferentes modos de produção capitalista (Fordismo/taylorismo e Toyotismo).

O PIBID é uma política que está sendo implantada na maioria das universidades e de acordo como Relatório 2009-2011 da CAPES (BRASIL, 2012) era o segundo maior programa de bolsas da CAPES e com tendência de crescimento, perdendo apenas para o programa de Demanda Social. Na configuração atual, podem participar do PIBID instituições públicas de ensino superior (federais, estaduais e municipais); instituições comunitárias confessionais e filantrópicas e privadas sem fins lucrativos, que participam da Reestruturação e Expansão das Universidades Federais (REUNI), do Exame Nacional de Desempenho de Estudantes (ENADE), do Plano Nacional de Formação de Professores da Educação Básica (PARFOR) e Universidade Aberta do Brasil (UAB). E também passou a atender IES privadas com fins lucrativos que atendem licenciandos do Prouni. De acordo com o Relatório 20092013 CAPES, o PIBID possui um percentual de 53\% de IES públicas e 47\% de IES privadas (BRASIL, 2013).

Conforme Relatório 2009-2013 CAPES em 2009 eram 3.088 bolsas e a meta era de alcançar, em 2013, o quantitativo de 75.000 concessões, mas foram aprovadas nos editais PIBID 201390.254 bolsas. O programa contempla: 195 IES; 313 projetos institucionais; 2.997 subprojetos; 5.398 escolas (BRASIL, 2013). Com base nos relatórios, observa-se que cada vez mais, vem aumentando o número de licenciaturas atendidas, o que é importante.

Mas depare-se com questões que necessitam ser levadas em consideração. O PIBID não pode ficar somente nesse âmbito, pois ao invés da política educacional investir na formação inicial nos cursos, investe apenas em bolsas que contemplam um pequeno número de alunos participantes. O PIBID não tem garantia de continuidade, ou seja, acaba sendo uma política compensatória, que mesmo sendo lei, não obriga o governo federal a disponibilizar recursos para o programa, pois se trata somente de uma lei de incentivo. Além disso, o PIBID pode ser suprimido por outro governo, por motivos como corte de gastos, redução de investimentos, assim como as bolsas de pesquisas, que alteram o valor de acordo com os programas de governo.

Além disso, diante do contexto de precarização da educação pública, o PIBID também abre precedentes para que instituições privadas participem do programa. Um dos motivos alegados é que as universidades privadas também apresentam problemas na formação inicial. Esse atrelamento das universidades privadas com as políticas públicas educacionais é no mínimo uma incoerência. O PIBID está se modificando enquanto programa pelo fato de se atrelar as universidades privadas.

Rosa (2014, p. 66) constatou que as Instituições de Educação Superior (IES) do Rio Grande do Sul (RS), no período de 2012 à 2013, que aprovaram projetos PIBID na área da Educação Física são em sua maioria instituições privadas, das 16 instituições 11 são privadas, sendo que a verba pública destinada a essas instituições "deveria ser prioridade para a educação pública. Mesmo tratando-se de um processo "democrático" a concorrência através 
de editais, não possibilita que todas as instituições públicas recebam programas com a característica do PIBID". Ainda segundo o autor:

\begin{abstract}
A extensão do PIBID às instituições privadas de Ensino Superior, nos permite assinalar que as reformulações do Ensino Superior estão cada vez mais atreladas às demandas de mercado. Os vários programas do Governo ao transferirem recursos públicos para IES privadas na forma de programas ou políticas de inserção e permanência no Ensino Superior acabam subsidiando o aumento do lucro dessas IES. Ao aderirem às propostas, essas passam a ser isentas por determinado período do pagamento de impostos. Logo, os recursos que poderiam ser recolhidos e aplicados nas instituições públicas não são mais arrecadados (ROSA, 2014, 57).
\end{abstract}

A educação superior vive uma crise, pois as universidades públicas que devem oferecer um ensino a todos e de qualidade, vem sofrendo implementação de políticas educacionais, as quais apontam, cada vez mais, para a precarização da educação pública brasileira. Percebe-se o quanto as políticas neoliberais influenciam nas políticas educacionais brasileiras. Exemplo disso são as várias normativas sobre o PIBID desde sua criação em 2007 até os dias atuais, sendo que no decorrer de cada novo edital, novas modificações são inseridas, muitas vezes ferindo questões públicas. Uma das normativas alteradas trata da questão das universidades privadas poderem participar dos editais de seleção do programa.

Há algumas décadas vivencia-se um período de intensa precarização da educação, sendo que para mudar este quadro e melhorar a qualidade da formação inicial de professores criam-se políticas educacionais. O PIBID entra nesse bojo, uma vez que é formulado pelo Estado como uma maneira de "solucionar problemas da formação inicial". Cabe ressaltar que o PIBID apresenta avanços com suas ações para a formação inicial de professores. Entre os principais aspectos favoráveis do programa, destaca-se o fato que ele garante minimamente condições de bolsas, condições materiais e condições de formação diferenciada para o acadêmico de licenciatura, ao coordenador e ao professor supervisor da escola. Ele garante condições mínimas que deveriam ser acessíveis a todos.

Mesmo tendo o PIBID se tornado lei, ele é trabalhado como programa e projetos, ou seja, na lógica das bolsas e dos editais, na qual somente alguns projetos são contemplados em detrimento dos demais. Assim, a universidade, como instituição pública, mantida com recursos públicos, acaba não abrangendo a todos. Ou seja, trata-se da lógica da "editalização" na universidade. Uma das limitações do PIBID, enquanto política pública educacional é ser um programa, porque isso não é uma política educacional de verdade na universidade, onde se concorre a editais. Essa "editalização" tem sido recorrente em toda a universidade, tanto para se conseguir bolsas para os alunos quanto para o financiamento da pesquisa e extensão, e até para o ensino, para se ter uma formação inicial de qualidade, deixando para o professor da universidade a responsabilidade e o mérito de concorrer a um edital. Os professores que tem seus projetos contemplados são docentes que dedicam tempo além da sua carga de trabalho, para garantir uma melhora na formação de professores. 
Neste momento histórico, a pergunta que fica é "por que o PIBID acaba se tornando um programa, por que é que não tem esse financiamento e incentivo para a universidade como um todo, para os cursos de licenciatura e para as escolas?". Corrobora-se com Puiati (2014, p. 159) que também se questiona "por que os subprojetos PIBID proporcionam vivências reconhecidas como importantes no ambiente escolar enquanto que os Cursos de Licenciatura não costumam proporcionar tais oportunidades, considerando que os envolvidos (alunos, professores formadores, escolas) são os mesmos nos dois âmbitos?"

A resposta seria porque esse é um programa atrelado a um determinado governo, é determinado por uma política de governo, em outras palavras, se acaba esse governo, acaba esse programa. Isso é uma coisa a se destacar, o papel do Estado nessa relação do modo de produção do capital. O PIBID muitas vezes aumentou a abrangência e o número de bolsas, o que é ótimo. Todavia, entra na lógica da "editalização" e, por isso, continua não sendo para todos, atrelado a programas, pois a seleção e participação ocorrem com o cumprimento dos critérios e perspectivas exigidas, no edital. Caso contrário, o subprojeto não será contemplado.

Com base nos problemas concretos da formação inicial, evidencia-se, mais uma vez, que o governo só propõe ações que não provocam mudanças significativas na educação, não atendendo, assim, as suas reais necessidades. Consequentemente, essas políticas educacionais levam a precarização da vida dos futuros trabalhadores e facilita o acesso do dinheiro público pelas instituições privadas, favorecendo cada vez mais os detentores do capital, sem contribuir para a transformação social. Segundo Frizzo (2012, p. 109):

Eficiência, produtividade, qualidade total, gerenciamento, todos esses argumentos se originam na esfera produtiva e de mercado. Ou seja, as alternativas apresentadas para solução dos problemas da educação recaem exatamente na proposição do mercado como regulador da vida em todos os aspectos e de todas as instituições.

As Instituições Privadas ao ficarem isentas dos impostos acabam onerando os cofres públicos, consequentemente, diminuindo o investimento na educação pública. Deste modo, percebe-se que o PIBID é uma política de caráter neoliberal, que defende os princípios do capitalismo, baseado no individualismo. Segundo a Comitê Nacional - Comitê Nacional em Defesa dos 10\% do PIB para a Educação Pública Já! (ANDES-SN, ANEL, CSP-Conlutas, Oposição de Esquerda da UNE, FENET, ExNEEF, SINASEFE, CFESS):

Este conjunto de políticas educacionais apresentadas tem uma perspectiva de educação baseada na mercantilização e na precarização do trabalho e ensino. Estas medidas particulares encontram a sua linha estratégica no Plano Nacional de Educação (PNE) sancionado pelo governo Dilma (PT) em 2014. Apoiado amplamente pelo setor empresarial, este documento apresenta várias questões que apontam para a privatização e o sucateamento da educação pública. O "simples" fato de retirar o caráter público da educação já demonstra que a perspectiva é de destinação de recursos públicos para a educação privada, intensificando os programas de repasse de recurso público direto ou através de isenções fiscais para as empresas educacionais, da creche à pós-graduação $(2015$, p. 17). 
O novo Plano Nacional de Educação (PNE 2014- 2024) foi construído e aprovado sem a participação dos principais sujeitos da educação e da comunidade. O PNE traz em seu conteúdo encaminhamentos oposto aos que são defendidos pelos trabalhadores da educação. Exemplo disso é a responsabilidade exclusiva do Estado na garantia da educação pública. Porém, no novo PNE foi aprovado que a educação pública pode ser garantida por parcerias público-privadas, ou seja, o Estado financiará o enriquecimento de empresas educacionais com o dinheiro público, ou seja:

\begin{abstract}
Quando se fala em investimento público em educação não se aponta para o investimento em "educação pública", mas sim em "educação", em que se incluem, na perspectiva de investimento público, os recursos alocados na esfera privada, atrelando e mascarando a destinação de $10 \%$ do PIB para a educação, pretendidos a serem atingidos ao final do decênio. $\mathrm{O}$ texto do PNE considera como investimento público a compra de vagas em instituições privadas, nacionais ou estrangeiras, em todos os níveis da educação, por meio dos programas com vistas à institucionalização como o Prouni, Pronatec, Ciência Sem Fronteira ou ainda, a compra de vagas na educação infantil em creches conveniadas, além de ampliar o endividamento estudantil através do Fies. O Estado se isenta do compromisso de garantir a universalização do direito à educação e passa, exclusivamente, ao processo de regulação e controle de resultados (COMITÊ NACIONAL, 2015, p.18).
\end{abstract}

Atualmente é necessário aplicar hoje $10 \%$ do PIB do Brasil no financiamento da educação pública para começarmos a recuperar o grande déficit na educação brasileira. Entretanto, no novo PNE, a aplicação do valor de $10 \%$ do PIB poderá ser feita até 2024 e como sabemos não será exclusiva para a educação pública, ou seja, haverá uma grande defasagem no financiamento educacional.

A partir do PNE 2014-2014 constata-se que as políticas educacionais são fortemente influenciadas pelas políticas neoliberais. Essas políticas educacionais para a formação de professores deixam evidente propostas que buscam frear o movimento dos professores, através da diminuição de investimentos em educação e inserção da iniciativa privada nessas políticas.

O PNE é uma legislação que "atende aos interesses privatistas do empresariado da educação; aprofunda a precarização dos trabalhadores em educação; e promove uma expansão sem adequadas condições", "retira da educação o caráter de direito social, garantido constitucionalmente, e privatiza o espaço da educação pública, através das parcerias públicasprivadas na perspectiva limitada a taxas de escolarização, intensificando a precarização do ensino" (COMITÊ NACIONAL, 2015, p. 6-18). Para Frizzo (2012, p. 73).

Essa contradição viva do capital pode ser expressada através do reordenamento do mundo do trabalho das últimas décadas, pautado entre outras questões, pela privatização do setor público (remetendo para a esfera privada os serviços essenciais da população), produção de tecnologia para diminuir o trabalho vivo na produção (sendo uma das causas do desemprego estrutural na sociedade) e a 
flexibilização e desregulamentação dos direitos trabalhistas (ao criar o exército de reserva funcional, os trabalhadores e trabalhadoras aceitam quaisquer condições de trabalho para, pelo menos, conseguir ter algum emprego).

O PIBID enquanto política para formação de professores, contribui para o curso de licenciatura. Assim, é preciso qualificar o curso, dar mais suporte e subsídios para a formação inicial, ao invés de se criar programas. É necessário incentivar a pesquisa e a extensão com bolsas dentro da formação, e não projetos paralelos. Para o governo é mais fácil e barato investir em projetos do que qualificar um curso para melhorar a formação de professores. Corroborando com Puiati quando afirma que:

\begin{abstract}
Não podemos naturalizar que as lacunas dos Cursos de Licenciatura serão sanadas ou amenizadas por um programa novo que não tem caráter principal na formação inicial de professores. Ainda que o programa PIBID faça isso, ressaltamos que são poucos os licenciandos que participam do programa. Por fim e pelos motivos sinalizados acima, ressaltamos que o programa PIBID tem importância sim para a formação inicial de professores. Porém, a base dessa formação ainda deve ser o Curso de Licenciatura (PUIATI, 2014, p.160).
\end{abstract}

Para o Comitê Nacional (2015, p. 9) as políticas educacionais precisam no atual momento uma reflexão aprofundada no que se refere as disputas de projetos de sociedade "a correlação de forças políticas possibilitou, ao governo federal, a consolidação de um processo de dominação de classe que se concretiza por meio de uma legislação que retira da educação o sentido de direito social garantido constitucionalmente de caráter público e gratuito".

Constatou-se que o PIBID enquanto política educacional é uma ação compensatória que acaba preenchendo lacunas da formação inicial de professores de Educação Física. É uma política de adesão individual, própria da política neoliberal, que prejudica e desmobiliza ações coletivas desqualificando a formação de professores, reproduzindo, com isso, a concepção de trabalhador que o mercado exige, individualista e competitivo para a empregabilidade. Com isso, identifica-se a relação do Estado na formulação dessas políticas educacionais. O Estado investe nessa ideia dos programas de incentivo à formação de professores e programas voltados para a Educação Básica e universidade, ao invés de criar políticas de Estado.

Além disso, a relação do PIBID com as políticas educacionais apresenta contradições, uma vez que se inverteu completamente a lógica, pois o PIBID é o tipo de política educacional que estabelece: para qualificar a formação de professores é necessário o investimento nesse tipo de programa. Observa-se que as políticas educacionais vão além do entendimento de uma intervenção do governo na resolução de um problema da educação, elas também estão relacionadas a manutenção do poder.

Percebe-se também que a implantação de políticas “paliativas" por parte do governo, pois pagar bolsas a poucos acadêmicos tem custo menor do que fazer investimentos maiores na qualidade da formação inicial, para assim contemplar a todos. O PIBID enquanto política 
educacional acaba se tornando a forma mais concreta da eliminação/manutenção, ao não atingir todos os acadêmicos da formação inicial. E ao entrar nessa lógica de investimento de dinheiro público em instituições privadas de ensino, tem acelerado a mercantilização da educação.

\section{CONSIDERAÇÕES FINAIS}

A sociedade brasileira apresenta-se com muita desigualdade social. Por isso, existe a necessidade da educação pública rever o seu papel e fazer o enfrentamento da posição política e pedagógica. A universidade está afastada das reais necessidades dos trabalhadores, servindo, cada dia mais, a interesses privados que estão utilizando verbas da universidade pública. Enquanto isso, os alunos da educação superior pública passam por dificuldades, não encontrando na universidade espaço para refletir e buscar soluções para essas questões.

Conclui-se que não há uma preocupação real com a qualidade do ensino oferecido aos acadêmicos em formação inicial. Enquanto política neoliberal o PIBID instiga $o$ individualismo entre alunos, professores, escolas e universidades, já que se trata de um processo de seletivo através de editais, não garantindo a participação no Programa de todos. Assim provoca um enfraquecimento dos envolvidos com o intuito de impedir uma reação coletiva, sendo a busca de melhores condições para inserção no mundo do trabalho acirrada pela responsabilização do indivíduo e a competição na educação.

Por fim, destacamos a necessidade de uma análise mais qualificada sobre o PIBID e a Política Neoliberal, sendo preciso considerar esta questão tomando como objeto de análise o modo como o programa é configurado na Instituição. Além disso, é preciso esclarecer as diferenças conceituais em ser "uma política absolutamente de adesão individual" e ser uma ação com "ênfase no individualismo".

A ação é desenhada pelas Instituições, já a política é alinhada pelo Estado, outrossim, a própria configuração do PIBID (Bolsistas - Acadêmicos, Professores da Educação Básica e da Universidade), já sinalizada a necessidade de uma nova configuração nas políticas pública de formação. Política esta que considere a Educação Básica como um importante contexto para a profissionalidade docente, devendo o aluno em formação, se formar no contexto do trabalho, em diálogo com os professores da Educação Básica e da Universidade. Há, neste caso, a indicação de uma ação colaborativa entre os parceiros envolvidos que deverá ser materializada pelas ações realizadas entre os sujeitos da Universidade e da Educação Básica.

\section{REFERÊNCIAS}

BRASIL. Ministério da Educação. Diretoria de Formação de Professores da Educação Básica - DEB. Relatório de Gestão 2009-2011 da CAPES. Brasília, Jul. 2012. p. 1-29. Disponível 9C) Rev. Triang. \begin{tabular}{l|l|l|l} 
Uberaba, MG & v.11 & n.2
\end{tabular} p. $77-90$ Maio/Ago. 2018 
em: $\quad<$ http://www.capes.gov.br/images/stories/download/bolsas/DEB_Pibid_Relatorio2009 2011.pdf $>$ Acesso em: 21 set. 2014.

. Ministério da Educação. Diretoria de Formação de Professores da Educação Básica - DEB. Relatório de Gestão 2009-2013 da CAPES. Brasília, 2013. p. 1-329. Disponível em: $\quad$ http://www.capes.gov.br/images/stories/download/bolsas/2562014-relatrorio-DEB2013-web.pdf>. Acesso em: 15ago. 2014.

COMITÊ NACIONAL. Em defesa da educação pública, gratuita e dos $\mathbf{1 0} \%$ do PIB para a educação pública já! Cartilha. Comitê Nacional em Defesa dos $10 \%$ do PIB para a Educação Pública Já! (ANDES-SN, ANEL, CSP-Conlutas, Oposição de Esquerda da UNE, FENET, ExNEEF, SINASEFE, CFESS). 2015.

FRIZZO, G. F. E. A Organização do trabalho pedagógico da Educação Física na escola capitalista. 2012, 265f. Tese (Doutorado em Ciências do Movimento Humano). Universidade Federal do Rio Grande do Sul, Porto Alegre, 2012.

MINAYO, M. C. de S. O desafio da Pesquisa Social. In: MINAYO, M. C. de S.; DESLANDES, S. F.; GOMES, R. (Org.). Pesquisa Social: Teoria, método e criatividade. 30. ed. Petrópolis, RJ: Vozes, 2011. p. 9-30.

PUIATI, L. L. Iniciação à docência na formação inicial de professores: possíveis relações entre cursos de licenciatura e subprojetos PIBID/CAPES na UFSM. 2014. 283f. Dissertação (Mestrado em Educação) - Universidade federal de Santa Maria. Santa Maria. 2014.

ROSA, C. L. L. PIBID: Formação Continuada para Professores de Educação Física. 2014. 114 f. Dissertação (Mestrado em Educação) - Universidade Federal de Pelotas, Pelotas, 2014.

SANTOS JUNIOR, C. L. A Formação de Professores Em Educação Física: a Mediação dos Parâmetros Teórico-Metodológicos. Tese (Doutorado em Educação). Faculdade de Educação. Salvador: Universidade Federal da Bahia, 2005. 194p.

TAFFAREL, C. N. Z. et al. Formação de professores de educação física para a cidade e o campo. Revista Pensar a Prática, Goiás, v. 9, n. 2, p.153-179, jul/dez. 2006. Disponível em: $<$ https://www.revistas.ufg.br/index.php/fef/article/view/166/154?journal=fef $>$. Acesso em: 15 jan. 2015. Doi: https://doi.org/10.5216/rpp.v9i2.166

. Formação de professores de educação física: diretrizes para a formação unificada. Revista kinesis, Santa Maria, v. 3. 0, n. 1, p. 05-191, jan/jul. 2012. Doi: http://dx.doi.org/10.5902/010283085726 